\title{
Neanderthal Man and Grimaldi Man: their Rôle in the Evolution of Mankind. ${ }^{1}$
}

\author{
By Prof. Réné Verneau, Muséum national d'Histoire naturelle, Paris.
}

\section{$\mathrm{T}^{\mathrm{H}}$} HE important discoveries in the domain of human palæontology which have been made in recent years, and those, far greater in number, which may be referred to the Neolithic period, have now made it possible for us to venture on an inquiry which seems to me not without interest. What, it may be asked, is the rôle that the nigritic element has played in the ethnology of the world in the past?

Wherever Neanderthal man occurs, he displays a remarkable homogeneity in character. It is no longer possible to regard him as physically or mentally diseased. He represents a primitive ethnic type which still retains a certain number of simian characters, as Schaafhausen and Huxley maintained, and as is acknowledged by all scientific workers of to-day who are free from prejudice. It is also incontrovertible, in my opinion, that Neanderthal man, taking his characters as a whole, can be brought into relation only with the nigritic group-a point which, I hold, it should not be difficult to demonstrate. But what is the rôle that he has played, and how great is its importance in the evolution of mankind? This is a point upon which there is complete disagreement among men of science. It is a question which appears to me to be sufficiently interesting to be discussed in some detail.

When it is admitted with Huxley, de Quatrefages, and Hamy, to mention a few only of those who have held this view, that there still exist in Australia representatives of the Neanderthal type who, however, in the course of ages, have undergone certain modifications under the influence of environment, the answer is simple. This type must have played a part of some note, since it has been able to perpetuate itself to this day in a country in which, as all agree, the environment has remained relatively stable. In Europe, so far as our present knowledge goes, the evidence for its existence is more difficult to follow. At the same time, de Quatrefages and Hamy held that certain characters observed in Neolithic crania and even in modern crania were atavistic manifestations of an ancestral state. On this view Neanderthal man should be regarded as one of our ancestors.

This theory, which is accepted by a number of anthropologists including myself, has been violently opposed by those who are unable to bring themselves to include in our ancestry a type which retained simian characters.

To-day, a whole school, which includes a number of eminent workers to whose knowledge and sincerity I render the fullest homage, and who for the most part call themselves evolutionists, maintains that Neanderthal man has bequeathed no single drop of his blood to modern man, and that Homo Neanderthalensis is a distinct species which has been replaced by Homo sapiens. To dispute a theory which is in the fashion is always an ungrateful task, especially when one appreciates the great merit of one's antagonists. Nevertheless, I may perhaps be permitted to set out the arguments of those who uphold these new ideas and the reasons which forbid me to agree.

1 Translated from the Huxley Memorial Lecture for I924 of the Royal Anthropological Institute, delivered on November 25 .
The palæontologists, relying for their argument upon the extinction of various species of animals during the geological ages, maintain that man is no exception to the general rule. I agree without the slightest qualification that human beings are subject to the great laws which govern other forms of organic life. But we must discover which of these laws is responsible for the disappearance of those species which have become extinct. To me there can be no doubt that that law is the adaptation of the organism to the environment. When the environment undergoes profound modification, as was the case in past geological ages, the organism, being no longer in harmony with the new conditions of existence, which it is unable to modify and to which it cannot adapt itself, must perforce disappear. In the case of man, however, the facts must be looked at from a different point of view. Although it is true that from the beginning of the Quaternary, that is to say from that point of time from which we can follow up man with certainty, changes in the environment have taken place, they have not been so considerable as to make it impossible for man to adapt his organism to the new conditions. There is proof of this in the remains of man's handiwork which are found at every level. There is another consideration which is not taken into account: the emigration or extinction of the Pleistocene species, whether they belonged to the warm or the cold fauna, takes place in close relation to climatic conditions, against which man, even of the most primitive type, is able to struggle in virtue of his intellectual powers. It follows then that while man is to a certain degree subject to the influence of his environment, he is able through progressive adaptation to evade the violent shock which brings about the disappearance of other species.

Among those who receive new ideas with their eyes closed and attach more importance to words than to facts, there are some who may object-and this has actually happened to myself - that it is not proved that Neanderthal man was an intelligent being. Their doubts are raised by the nomenclature applied to primitive man - or, at least, to one of his branches, now said to be extinct-and to modern man, who is known as Homo sapiens. The term sapiens is quite inappropriate, as it is applicable only to moral or intellectual qualities, and there is no specific reason for applying it to Homo sapiens to the exclusion of Homo Neanderthalensis. As regards the moral qualities of the latter we can only advance pure hypotheses ; but it is quite another matter in regard to his intelligence. Here I may leave the argument to one of the most eminent and at the same time one of the most firmly convinced upholders of the theory that Neanderthalensis became extinct at an early date, my learned colleague and friend, Prof. M. Boule. After having stated in his great work" Les Hommes fossiles" that certain backward peoples of the present day, whom nevertheless he classifies as Homo sapiens, are to be brought into relation with Neanderthal man, " if not from the point of view of physical characters, at least from the point of view of moral qualities" and by their mode of life, he adds, "the latter is already man, notwithstanding 
the morphological inferiority of his brain, and is in no way the precursor of man, since we find mingled with his bones the implements of stone that he knew how to make and the ashes of the fires he knew how to light and how to tend. Already his actions are those of modern savages; and if naturalists, abandoning their usual practice, were to base their classification of the beings they study upon intellectual qualities, they would have no specific ground for a separate classification of Neanderthal man and modern man; while, as we have already seen, it would not be possible to refuse him this distinction on the ground of his physical characters."

That is how the question stands. Homo sapiens is not marked off from Homo Neanderthalensis by his intellectual qualities, as we might be led to suppose from the specific title which has been bestowed upon him. It is by his physical characters that he is separated from modern man, even in the case of peoples of the most primitive type. This is well shown by an examination of the cranial characters of Neanderthal man and comparison with modern types such as Australian, Bushman, etc.

From what has been said, it emerges that there is no character which has been observed in Homo Neanderthalensis which is not to be found in modern man, though principally among the nigritic races. But, as Prof. Boule has very rightly said, it is not the existence of an isolated character which is of interest to us from this point of view. "It is the presence, the conjunction, the accumulation of these characters in each of a whole series of crania" which has value. Each skull in the Australian series of this type with which I have dealt presents such an accumulation of characters of the Neanderthal race that it is impossible for me not to accept a close relationship between the two groups. To my mind, the Neanderthaloid Australian skulls prove that the Neanderthal race has not " died out without leaving any descendants." It follows that this nigritic race, which played an important part in antiquity, has also made its influence felt in man of to-day.

But if the Neanderthal type [Rhodesian man] persisted in Africa, why could he not have persisted in Australia, and why should he not have submitted there to the influence of environment as he did in Rhodesia? Could he not have been modified as Rhodesian man was in some degree when he acquired the upright attitude ? When we consider the enormous distance in space and time which separates the Neanderthaloid Australians from our Mousterians, it is difficult to conceive that the type could have perpetuated itself in New Holland without modification. This would be a denial of the influence of environment which I could not accept.

On the other hand, it may be argued that, judging by its flora and archaic fauna, the Australian environment does not appear to have undergone any great change. It is this which explains precisely how it is that the characters of the southern tribes have only suffered some attenuation. To maintain that the conditions of existence of these natives have remained absolutely stable, and to hold that the Australians have not progressed, is an untenable hypothesis. The main characteristics of the material culture of the Australians show that this is not the case. All this denotes that, however backward they may be, the Australians have evolved and they no longer stand where stood the Mousterians in Europe. It would not be credible that while their intelligence developed their physical characters remained immutable. But their evolution has been very slow and they have preserved a group of Neanderthal characters sufficiently well-marked to lead me to regard them, as Prof. Boule has done elsewhere, as derived from the same source as Homo Neanderthalensis. These characters are beyond question nigritic, and it is difficult to refuse to admit that this nigritic element, which played a part in Europe in the first part of the Quaternary age, has not bequeathed its blood to modern man, notably the South Australian and apparently in a lesser degree to other Melanesians.

Let us now see if traces of it can still be found in Europe at the present day. There have been found on many occasions in prehistoric, historic, and modern burials, skulls which reproduce in part the characters of the ancient fossil race of which we are speaking. There are specimens in many museums and since 1882 the authors of "Crania Ethnica" have described a number of examples. Additions are being made to these observations continually. In I9I4, for example, Verworn recorded two skeletons found at Obercassel, near Bonn, in a hearth of the Reindeer age. He noted that they presented certain resemblances to the races of Cro-Magnon and Chancelade, and, in addition, showed Neanderthal characters. Beside this nigritic bestial type there is another, more highly developed, representatives of which are to be found dating from the Quaternary epoch. This is the negro type which I have called the race of Grimaldi, as the first examples were found near the Italian frontier in the territory of a commune bearing this name. The physical characters of Grimaldi man show close resemblances to the negro type.

In the presence of so many characters which are frankly nigritic, and of which some indeed recall those of Homo Neanderthalensis, it must be recognised that, at one point in the Quaternary period, negroid individuals lived in Europe. It may, however, be asked whether the two subjects from Baoussé Roussé were not negroes who arrived there accidentally and disappeared without exercising any influence in Europe. My researches on this problem have led me to discover in several museums in Southern Italy modern crania with characters which incontestably recall those of the Grimaldi race. I have even found two living subjects who came from the Graian Alps, where it is difficult to believe that any negro could have penetrated in recent times; these showed a number of the cephalic characters of the Baoussé Roussé negroids. When once attention was directed to this point observations multiplied. Skeletal remains of negroids have been found in collections from France, Switzerland, Italy, and North Africa. Some dated from the Upper Palæolithic (a series of crania from the rock shelters of $\mathrm{La}$ Mouillah on the frontier of Western Algeria), others from the shell heaps of Tebessa, of which the age is disputed, and others from the Lower Neolithic of the Province of Oran. In North Africa, the negroid element must have formed the ethnic substratum of the whole of the Berber country. In Europe we find it in the Neolithic age in Brittany, in Switzerland, in Illyria, the Balkans, etc.; in the Bronze and early Iron ages in

$$
\text { NO. } 2877 \text {, vOL. I I } 4]
$$


Switzerland, in Southern Italy, and so on. It is plausible to attribute to atavism the prognathism, often very pronounced, and the retreating chin which is to be observed to-day among certain individuals who do not otherwise exhibit nigritic characteristics, either in the hair or in the coloration of the skin. As I wrote in I906, " since we still find to-day so many traces of an ethnic type with characters which recall those which I have observed in the Grimaldi race, we are compelled to believe that this race was formerly represented among us by a whole group." I might add, however, that the same type must have been equally strongly represented in North Africa.

To sum up, the division of mankind into two entirely distinct species, Homo Neanderthalensis and Homo sapiens, the first long extinct and leaving no trace behind, does not appear to me to be justified. The Neanderthaloid characters of the Australians indicate a close relationship with our Mousterian man, while on the other hand, certain features in Neolithic or modern skulls found in Europe are to be explained as due to atavism. The race of Neanderthal, thoroughly nigritic in type, has continued to play its part among us, as it has in Africa, Australia, and elsewhere. Observations made on the Pleistocene skeletons of Wadjak and on remains from the mounds of Nebraska lead me to believe that the same element has entered into the ethnology of Java and the New World.

In the case of Grimaldi man, no doubt is possible. The traces can be followed in Europe almost step by step from Aurignacian times to our own day. In North Africa its existence is equally apparent though it may not be possible to fix the date of its appearance with precision. Another nigritic element, the Papuan, has just been noted in Tonkin by M. Mansuy on sites which take us back to a Neolithic period of very high antiquity. In $\mathrm{x} 879, \mathrm{~A}$. de Quatrefages observed similar characters in a fossil cranium from a cave near Lagoa Santa in Brazil. P. Rivet has found the type represented in some abundance in the rock-shelters of Paltacalo in Ecuador; and it appears among the Pericues, an extinct tribe of Lower California, which $\mathrm{H}$. ten Kate had already recognised to be clearly related to the Melanesians. I myself have pointed out the existence of this strongly marked type among the Tunebos of Colombia. From California to the extreme south of
America the nigritic element has played a part of sufficient importance to leave its traces everywhere.

From all these facts I conclude that mankind in the beginning was represented by one or more nigritic types of marked bestiality and retaining several simian characteristics. These primitive elements have evolved and have given rise to the great negro stocks of to-day, the African and the Melanesian. This evolution has been progressive. We have a proof, in my opinion, in the intermediate types found at Talgai and Wadjak. These intermediate types, while evolving in some degree, have perpetuated themselves to the present day in special conditions, as, for example, among the nonNeanderthaloid Australians and the New Caledonians. Our Grimaldi negroids are too far removed from Neanderthal man to allow us to suppose that they are immediately descended from him, especially if the interval separating them is relatively small. Where could this type have become established? I do not know. On a priori grounds we think of North Africa; but the negroids of North Africa appear to be more recent than those of Baoussé-Roussé.

The conclusions which emerge may be summed up in a few lines :

(I) Primitive man exhibited simian characters pointing to relationship with the anthropoids. This archaic type has not become extinct; it has evolved in accordance with its environment. Traces of it occur very sparsely in Europe, but are readily discernible in South Australia.

(2) This primitive type was followed by a more developed type in which the simian characters have gradually disappeared, but in which the nigritic characters are retained in a marked degree. Although it plays only a very insignificant part among ourselves, this is not the case in other parts of the world.

(3) Recent discoveries lead us to suppose that a nigritic element has everywhere preceded the yellow and white races.

In truth, there are too many gaps in our knowledge for it to be possible to follow step by step the evolution of man in time and space. The links which are needed to establish the filiation of the races are missing. Yet it seems to me that my view of the question is more nearly in accord with the facts than that which accepts a gap between early man and man of to-day.

\section{The Biological Action of Light.}

THe beneficial action of a change of climate, especially when a sunny place is chosen, is well known: why the change is so frequently more effective than other therapeutic methods is a question which has only recently been investigated scientifically-one of the many examples of the lag in the acquirement of scientific knowledge behind popular opinion. Apart from the mental effects of a change of scene, benefit may be derived from both the cooling power of the air and also the incidence upon the body of the sun's rays. C. Lee Pattison (Lancet, October I8, r924) has recently given an account of the therapeutical effects of ultra-violet radiations, while C. Dorno (Naturwissenschaftliche Umschau d. Chem. Zeitung, October r924) has considered the subject more from the physical aspect. The effects of the different parts of the spectrum are not the same, the ultra-violet rays being the most active therapeutically. They are present in the atmosphere to a much greater amount, relatively to the infra-red heat rays, in summer as compared to winter, but their activity is confined to the superficial layers of the skin, since they have only a low penetrating power. It must be remembered also that these rays are largely absorbed by glass, and therefore exposure must be made in the open air or directly to a source of ultra-violet light.

It appears possible that rays of a shorter wave-length than $290 \mu \mu$, which do not occur in the solar radiation, may be still more effective than the latter. The skin pigment absorbs chiefly the visible yellow and green rays, with the production of heat, which is then radiated outwards by the skin, while the red and short

$$
\text { No. } 2877 \text {, VOL. I I } 4 \text { ] }
$$

